TAURION, Cezar. Big data. Rio de Janeiro: Brasport Livros e Multimídia Ltda., 2013.

\title{
RESENHA DO LIVRO BIG DATA
}

O autor Cézar Taurion relata nesse livro o tema que se tornou um "buzzword" do mercado quando se fala da percepção dos movimentos da rede social. O objetivo principal do livro é descrever em linguagem simples, inteligível a todos, o que realmente é Big Data, ele procura desmistificar que a mídia tem noticiado como a solução para a inteligência do mercado. $O$ autor é um estudioso em inovação tecnológica, e foi o "evangelista" da IBM para a tecnologia de ponta, e a sua relação com a sociedade, ele foi um dos primeiros a escrever sobre computação em nuvem e agora nesse novo livro descreve para nós os conceitos e recursos do Big Data. Nesse trabalho, ele endereça tanto a leigos como a profissionais que atuam nos territórios da tecnologia, como podemos ver nos tópicos técnicos os conceitos importantes voltados aos profissionais da área de TI.

O livro está dividido em três grandes grupos de assuntos sobre Big Data:

1. Conhecimento sobre o Big Data propriamente dito, que constitui a maior parte do livro, neste tópico, o autor trata o que é Big Data, qual é a razão do seu aparecimento, quais são as aplicações resultantes do seu aparecimento, estudos de casos e a sua aplicabilidade nas empresas. Podemos pontuar que a descrição sobre o surgimento do Big Data é literal, isto é, a quantidade de dados gerados atualmente é muitíssimo grande (Big), e, essas informações vêm de todos os lados (Data), a origem dos dados vem desde sensores e câmeras de segurança, que praticamente cobre todas as cidades, até as fotos clicadas por mais de um bilhão de smartphones, sem falarmos dos todos os computadores existentes e posts dos textos dos chats nas redes sociais. Segundo o livro, no final do ano de 2015, geraremos quase oito zetabytes ( $10^{21}$ bytes) de dados, na realidade, $90 \%$ dos dados armazenados atualmente são produzidos nos últimos dois anos. A explosão da Internet das Coisas contribui pesadamente para isso, gerando uma

\footnotetext{
${ }^{1}$ Pós-doutor em Ciências da Comunicação pela ECA USP. Doutor e Mestre em Comunicação e Semiótica pela PUC SP. Engenheiro pelo ITA. Pesquisador do GESC3 - Grupo de Estudos Semióticos em Comunicação, Cultura e Consumo. E-mail: lawrence@ pucsp.br
} 
quantidade de dados que exige coleta e análise. O autor resume o Big Data com uma equação: Big Data $=$ volume + variedade + velocidade + veracidade, tudo agregando + valor. Existem muitas razões para que se caminhe em direção a Big Data, uma delas é a busca da computação cognitiva, empresas como a IBM já desenvolve "learning machine" que aprende com dados, e quanto mais dados, mais os algoritmos das máquinas aprendem. A utilização das técnicas de Big Data acelerará o processo de pesquisa e desenvolvimento (P\&D) e em combinando o seu uso com as técnicas de data warehouse gerará um impacto ainda maior. A sua aplicação é muito vasta, um dos exemplos, dentre muitos, citados no livro é o de Flu Trends da Google, que consegue identificar indícios de propagação de gripe antes da apuração dos números oficiais, demonstrando mais rapidamente a situação real, auxiliando dessa forma o combate à epidemia.

2. O segundo tópico está endereçado para os leitores que querem aprofundar-se nos aspectos técnicos do Big Data, tais como, qual é a infraestrutura requerida, principais tecnologias de software utilizadas, e, em especial, é dedicado um capítulo para descrever Hadoop, que muitas vezes é confundido como Big Data pelos programadores, mas o livro procura definir melhor o papel das tecnologias envolvidas, localizando-as dentro de uma arquitetura técnica de fácil entendimento. Essa explicação permite-nos entender como funcionam os aspectos de interfaces cognitivas que Big Data tem com os usuários finais. Essa segunda seção tem um papel interessante de introduzir alguns "dialetos técnicos" de forma suave sem a roupagem herméticas da Ciência de Computação, no nosso entender, o leitor leigo, mesmo muito pouco letrado em tecnologia pode aventurar-se em ler esses capítulos sem receio.

3. O último tópico foca os vários aspectos de recursos humanos que são influenciados pelo aparecimento do Big Data, na verdade, todos sabem que cuidar dos dados e informações das instituições sempre foi uma tarefa importante e crítica, mas sempre ela é deixada para trás pelas outras atividades mais urgentes consideradas de missão crítica. Segundo o livro, as atividades de tomadas de decisão baseadas nos resultados das pesquisas do Big Data em redes sociais passaram a ser protagonistas, portanto, novas funções tais como CDO - Chief Data Officer tornam-se mandatórias.

No final, Taurion arremata com o resumo da seguinte forma: "Big Data nos abre as portas da "Intelligent Economy" ou economia inteligente com base no fluxo contínuo 
de informações, que devem ser monitoradas e analisadas. A competitividade e competência essencial das empresas fatalmente terão parte do seu alicerce nos resultados nas informações providas pelo Big Data. Como foi mencionado anteriormente, dados de IDC mostram que, esse volume deve chegar a oito zetabytes já em 2015.”

O Taurion conclui, "hoje, Big Data é visto como um hype, sim, pode ser verdade, mas é um tsunami no alto mar ainda, e não pode ser ignorado. Quando se estabilizar," continua o autor, "será chamado apenas Data, com um volume absurdamente grande, mas juntamente com os outros v's (velocidade, variedade, veracidade e valor) estarão combinados para gerar novos processos, tratar e analisar os dados será tão importante para as organizações quanto os demais fatores, como recursos humanos, tecnológicos e financeiros. As empresas simplesmente não viverão sem analisar dados continuamente."

\section{REFERÊNCIAS BIBLIOGRÁFICAS}

TAURION, Cezar. Big data. Rio de Janeiro: Brasport Livros e Multimídia Ltda., 2013.

Artigo submetido: 10/06/2014

Artigo aprovado: 15/06/2014 